\title{
NOTAS SOBRE LA EXÉGESIS DE LEONCIO DE NEÁPOLIS EN SU APOLOGÍA CONTRA LOS JUDÍOS
}

\section{Introducción}

Leoncio ( $c$ a. 590-650) fue obispo de Neápolis (actual Limosol), en Chipre, y su discreto legado literario contendría un escrito apologético contra los judíos, del que da cuenta -entre otros- un fragmento que transmite el autor bizantino tardío Eutimio Zigabeno $(\dagger c a .1118)^{1}$. Las presentes notas tienen por objetivo considerar algunos aspectos más destacados del tratamiento que ese autor hace de ciertos pasajes bíblicos en dicha obra ${ }^{2}$.

El fragmento de la Apología contra los judíos de Leoncio de Neápolis trata de «los signos del advenimiento de Cristo», argumentando a partir de tres pasajes del AT, a saber: Miq 4,3; Jr 38,34 (LXX; 31,34 TM) e Is 11,6-8. El tema fundamental en debate es el cumplimiento (o no) de tales profecías, como prueba de que Jesucristo es el Mesías prometido y ya arribado. Tal parece haber sido -según se señala expresamente- «la muy famosa cuestión de los judíos» ${ }^{3}$, que también presentaba Justino (†ca. 165)

1 Sobre Leoncio, cf., p. e., V. DéRoche, Études sur Léontius de Néapolis (SByU 3). Upsala, 1995, passim; A. LoUTH, «Leonzio di Neapolis», en DPAC2 2 (2007), pp. 27862787; sobre el fragmento de la Apología contra los judíos, cf., p. e., V. DÉRoche, L'authenticité de l'Apologie contre les juifs de Léontios de Néapolis», en BCH 110 (1986), pp. 655-669; ID., L'Apologie contre les Juifs de Léontios de Néapolis», en TMCB 12 (1994), pp. 45-104.

2 Este trabajo surge en el marco del proyecto de investigación del Instituto de Filología Clásica, Sección de Filología Medieval, de la Facultad de Filosofía y Letras de la Universidad de Buenos Aires, UBACYT 20020130100007 BA, años 2014-2017, «Hagiografía, homiliética y contexto sociocultural en Bizancio tardoantiguo: ecdótica del corpus de Leoncio de Neápolis» (Resolución CS 921/14), dirigido por el Prof. Dr. Pablo A. Cavallero.

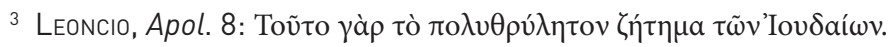


en su Diálogo con Trifón, refiriéndose igualmente a Miq 4,1-7. En efecto, el apologista, tras citar el texto bíblico, señala que los «maestros» de los judíos «reconocen que todos estos dichos de este pasaje se refieren al Mesías», pero acota que estiman, o «que todavía no ha venido», o que, si así fue, aún no se ha hecho presente de forma manifiesta: «Entonces acontecerán las cosas dichas» en la Escritura, pero hasta ese momento no hay «ningún fruto de los dichos de la profecía» ${ }^{4}$.

Leoncio aborda cada uno de los tres pasajes veterotestamentarios, tratando de destacar brevemente lo que -en su opinión- ya se ha cumplido de los mismos en la vida de Jesucristo y, asimismo, en el régimen inaugurado por él. Y comienza refiriéndose a Miq 4,3, que cita con dos leves diferen-

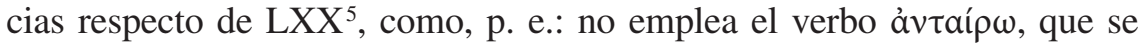
prefiere en la edición del AT griego, siguiendo el Codex Vaticanus y el Freer, sino aíp $\omega$, atestiguado por la mayoría de las demás versiones de $\mathrm{LXX}^{6}$; ade-

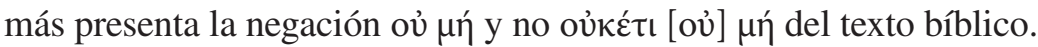

$\mathrm{Su}$ argumentación a partir del pasaje de la Biblia es escueta: lo señalado por la profecía se habría cumplido en tiempos del nacimiento de Cristo, cuando, bajo el gobierno de los romanos, se obtuvo la paz en todo el orbe, por cuanto que entonces, sin guerras, los pueblos se dedicaron al trabajo agrícola: «... sometido todo el pueblo al imperio de los romanos, todos estuvieron en paz, y sin guerrear ya entre sí, por estar bajo una misma cabeza, se tornaron a la agricultura» (Leoncio, Apol. 11-13) 7 .

El autor previene objeciones, señalando que la Escritura habla aquí

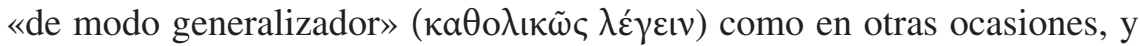

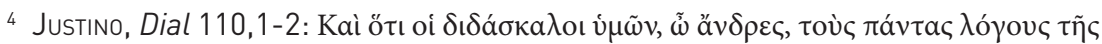

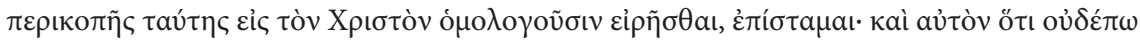

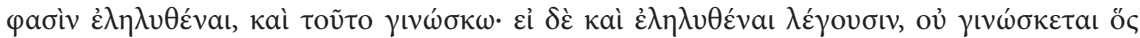

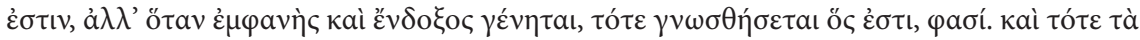

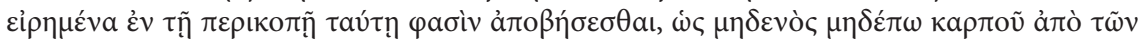

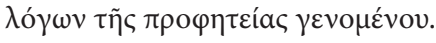

${ }^{5}$ Cf. Leoncio, Apol. 1-2. Respecto del pasaje de Miq y el texto paralelo en Is 2, cf., p. e., J. M. Powis Smith / W. HAyes Ward / A. Bewer Julius, A Critical and Exegetical Commentary on Micha, Zephaniah, Nahum, Habakkuk, Obadiah and Joel (The International Critical Commentaryl. Edimburgo, 1912, pp. 83-84. Acerca del uso de estos textos en la polémica antijudía de la Antigüedad cristiana en general, cf., p. e., H. ScHRECKENBERG, Die christliche Adversus-Judaeos-Texte und ihre literarisches und historisches Umfeld (1.-11. Jh.) (EHS.T 172). Frankfurt - Berna, 1982, pp. 52-53, 72-73.

${ }^{6}$ Cf. A. Rahlfs / R. Hanhart (eds.), Septuaginta, id est Vetus Testamentum graece iuxta LXX interpretes. Dua volumina in uno. II. Libri poetici et prophetici. Stuttgart, 22006, p. 515.

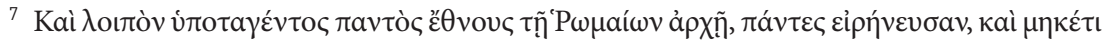

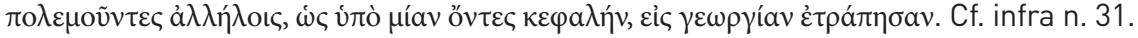


cita Dn 3,38 (donde se indica que no había profetas en Israel, aunque no era el caso) entre muchos otros ejemplos posibles ${ }^{8}$.

Los otros dos pasajes bíblicos considerados reciben un tratamiento menor. Así, la cita de Jr 38,34 (LXX; 31,34 TM) coincide con la versión de $\mathrm{LXX}^{9}$ y Leoncio solo comenta que los «muchos y grandes signos» de Cristo provocaron que «todos, desde el pequeño hasta el grande», lo reconocieran, tal como lo testimonian «no solo [...] los evangelios, sino también [...] los escritos cronísticos de los hebreos y de los historiógrafos entre los griegos» ${ }^{10}$.

Por su parte, el texto de Is 11,6-8 se cita con algunas variantes respecto de $\mathrm{LXX}^{11}$, como, p. e.: se emplea el tardío ả $\rho v o ́ c$ en vez de ả ṕv; a la

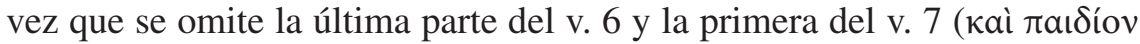

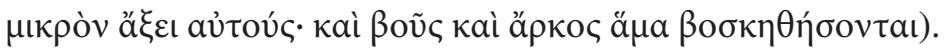

En esta oportunidad, el comentario de Leoncio es detallado ${ }^{12}$ y comienza destacando que los distintos animales mencionados hablan de «diferentes caracteres de seres humanos» y su pacífica convivencia alude «al único rebaño de ellos», esto es, «a las Iglesias» ${ }^{13}$. Precisa luego a qué tipo de persona se aplica cada bestia, como igualmente el sentido del alimento que reciben todas: «La unicidad de la fe» ${ }^{14}$. Asimismo se indica que la figura del pastor, «hombre canoso»y «niño», habla de alguien «sensato»y «grande por la virtud», a la vez que -como el pequeño del texto bíblico-

8 Cf. Leoncio, Apol. 13-16.

9 Cf. Leoncio, Apol. 2-4. Acerca de la diferencia del texto de Jr en TM y LXX, cf., p. e., G. P. Couturier, «Jeremías», en R. E. Brown / J. A. Fitzmyer / R. E. Murphy (eds.), Comentario bíblico «San Jerónimo» 1. Madrid, 1971, p. 789; L. Alonso Schökel / J. L. Sicre Díaz, Profetas I. Isaías. Jeremías. Madrid, 1980, p. 419; J. Bright, Jeremiah. Introduction, Translation, and Notes (AncB 21). Garden City, NY, 1965, pp. LVI-LXI; J. P. HyAtT / S. R. HoPPER, «The Book of Jeremiah. Introduction and Exegesis», en G. A. ButTRIck (ed.), The Interpreter's Bible. The Holy Scripture the King James and Revised Standard Version with General Articles and Introduction, Exegesis, Exposition for Each Book of the Bible 5. Nueva York - Nashville, 1956, pp. 788-791.

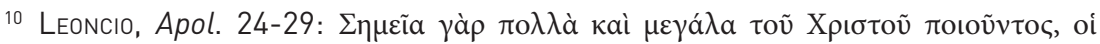

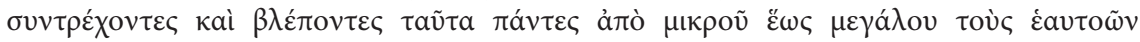

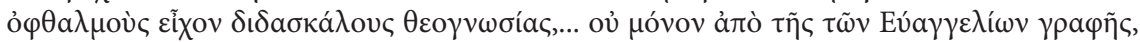

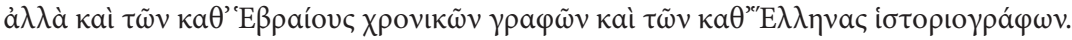

11 Cf. Leoncio, Apol. 4-8.

12 Cf. Leoncio, Apol. 29-56.

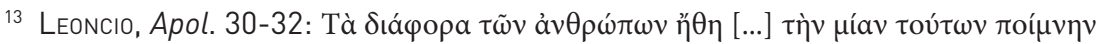

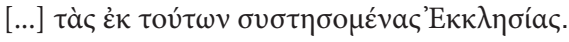

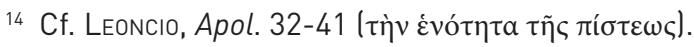


«falto de maldad y humilde», «sobrio y frugal» ${ }^{15}$, en tanto que su inmunidad y poder frente a la maldad se atribuye a la «enseñanza eficaz», a la «vida conforme a Cristo»y al poder de la cruz ${ }^{16}$.

A continuación quisiera comparar algunos aspectos de la lectura de los textos bíblicos que hace Leoncio de Neápolis (según el testimonio del fragmento de su Apología transmitido por Eutimio Zigabeno) con ejemplos de la exégesis de esos mismos pasajes escriturísticos en la tradición cristiana previa.

\section{En cuanto a Miq 4 e Is 2}

El uso de la profecía de Miq 4 y del oráculo paralelo en Is 2 es considerable en la tradición cristiana anterior a Leoncio. Ya se mencionó el caso de Justino ( $† c a$. 165), que se vale de estos textos para señalar, en general, el acceso de los gentiles a la fe y el anuncio de la fe cristiana por parte de los apóstoles ${ }^{17}$. Pero cabe destacar, además, que este apologeta griego emplea la noción de «doble advenimiento de Cristo»: pasible y glorioso ${ }^{18}$, para enfatizar que ya ahora entre la primera venida (acontecida) y la segunda (por venir) se da un cumplimiento parcial de las profecías veterotestamentarias en el cambio de vida operado en los creyentes por la adhesión a la fe que los conduce a la paz ${ }^{19}$.

Más adelante, Jerónimo $(\dagger c a .420)$ recurre reiteradamente a estos pasajes proféticos, y en su Comentario a Miqueas se expresa claramente-como es su estilo- en oposición a judíos y milenaristas, señalando que los oráculos hacen referencia a la primera venida de Cristo, en la que se reúne el resto del

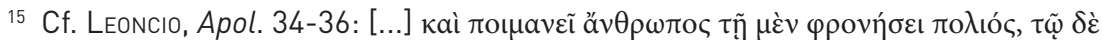

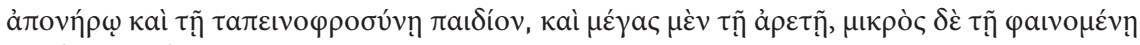

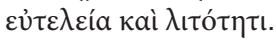

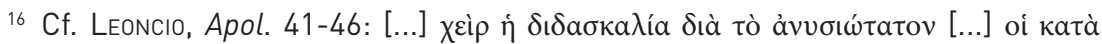

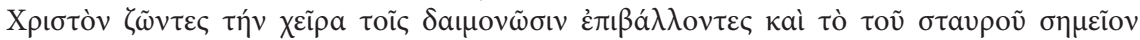

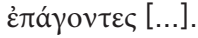

17 Cf., p. e., Justino, Dial. 109,1; también Dial. 24,1-2; Apol. 1,39,1-3.

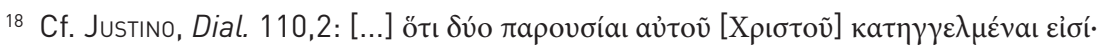

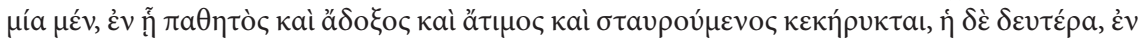

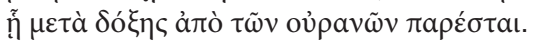

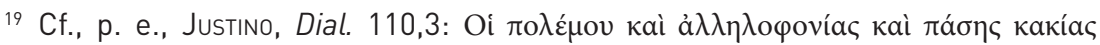

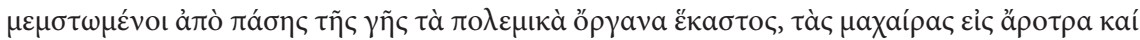

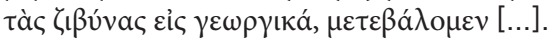


pueblo fiel a $\operatorname{Dios}^{20}$. El aspecto escatológico reaparece cuando, nuevamente con su tono amenazante, enfatiza que la Palabra que sale de Jerusalén juzgará a los creyentes por sus pecados, en tanto que demostrará que los judíos ya están condenados ${ }^{21}$. En otros textos, el exegeta latino apela a estos pasajes del AT para aludir, en general, al anuncio del Evangelio ${ }^{22}$, en tanto que su Comentario a Isaías habla de la paz que se logró en el mundo, hacia tiempos del nacimiento de Jesucristo, por acción del Imperio romano, donde la mayoría de los habitantes comenzó entonces a dedicarse a la agricultura ${ }^{23}$. Igualmente en Teodoreto de Ciro ( $\dagger c a$. 466) retorna este tópico de la paz que llega porque los romanos someten los pueblos a la unidad y se desarrollan las actividades respectivas, como la agricultura ${ }^{24}$. También este autor antioqueno destaca el tema de la predicación de la fe por los apóstoles ${ }^{25}$.

Aunque estas son las lecturas más pormenorizadas de ambos oráculos del AT, se pueden indicar otros usos menores, como el de Ireneo de Lyon ( $\dagger c a$. 202), que apela a dichos pasajes al argumentar que la nueva Alianza comenzó con la venida del Señor, que trajo la reconciliación, la paz y la vida, y no así con el retorno de Israel de Babilonia ${ }^{26}$. Orígenes

20 Cf. Jerónimo, Com. Mich. 1,4,1-7 (472): [...] ludaeos et eorum erroris heredes ad mille annorum referre imperium Christi atque sanctorum [...] sed de primo aduentu Christi, in quo collegantur reliquiae claudicantis, et gentes ante saluantur.

${ }^{21}$ Cf. JerónImo, ibid.: Nos enim quasi peccatores iuxta operum nostrorum mensuram iudicabit, illos [ludaeos] uero ut impios et negatores non iudicabit, sed arguet condemnatos; también Com. Is. 1,2,4 (29-30); 2,5,24 (79). Acerca de una visión general del pensamiento de Jerónimo sobre el judaísmo, cf., p. e., H. SchreCKENBERG, Die christliche Adversus-Judaeos-Texte, pp. 333-339.

22 Cf., p. e., Jerónimo, Com. Zac. 3,14,8-9 (884); Com. Ez. 11,39 (543); 14,47 (706); Com. Is. 1,2,2-3 (27-29); 11,40,9-11 (458); 12,42,1-4 (480); 14,51,4-5 (560); 17,60,4 (695); Com. Jl. 2,28-32 (197); además, Com. Mich. 1,4,1-7 (469).

${ }^{23}$ Cf. Jerónimo, Com. Is. 1,2,4 (29-30): Orto autem Domino Saluatore, quando sub praeside Syriae Cyrino prima est in orbe terrarum facta descriptio et euangelicae doctrinae pax Romani imperii praeparata, tunc omnia bella cessauerunt et nequaquam per oppida et uicos exercebantur ad proelia; sed ad agrorum cultum, militibus tantum legionibusque Romanis contra barbara nationes bellandi studio delegato [...]; cf. también Com. Is. 5,19,24-25 (200); Ep. 106,1, e infra n. 31.

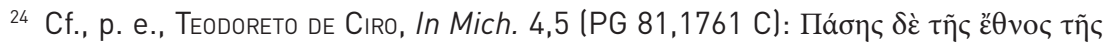

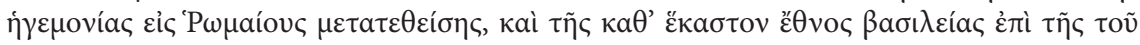

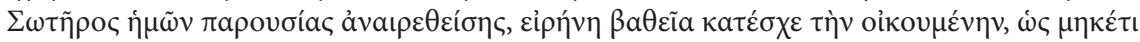

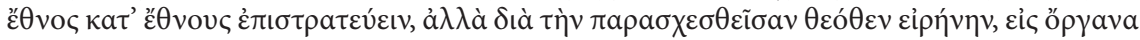

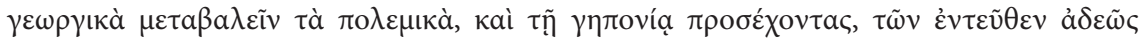

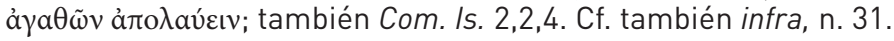

25 Cf. Teodoreto de Ciro, In Mich. 4,1-3 (PG 81,1760 BD).

26 Cf. IReneO, Adv. haer. 4,34,4. 
(†ca. 254) evidencia su interés exegético al valerse de esos textos para ejemplificar el caso de profecías que toman de otra ${ }^{27}$, y en una ocasión para alegorizar sobre las armas ${ }^{28}$. Aunque quizá sea más digno de destacar que, argumentando contra la acusación de Celso de que los cristianos son apóstatas del judaísmo, emplea tales pasajes para evidenciar que la Iglesia se edifica sobre las profecías, aunque su anuncio es universal y hace de los hombres hijos de la paz ${ }^{29}$.

Eusebio de Cesarea $(\uparrow 339)$ recurre a menudo a estos textos al hablar, en general, del anuncio de la nueva Alianza ${ }^{30}$. Pero, conforme a su visión teológica del régimen de Constantino, le gusta destacar que por la acción de los romanos se ha logrado la paz y la unidad profetizadas, y luego, además, la superación del paganismo ${ }^{31}$. En Basilio de Cesarea $(† 379)$ solo hay un pasaje en que se apela a tales textos para instar a la paz entre los creyentes ${ }^{32}$.

Por su parte, también en el Occidente latino se advierte un considerable empleo de las profecías en cuestión. Así Tertuliano (†ca. 220) recurre a ellas en su Tratado contra los judios para contraponer la nueva Ley de la mansedumbre a la antigua de la dureza, a la vez que enfatiza la paz que se da en el nuevo régimen, destacando también el cultivo de la tierra ${ }^{33}$. Pero en su disputa contra la separación que Marción introducía entre AT y NT se vale de esos textos para mostrar que no hay dos Cristos: uno para los judíos, el hecho por el Creador, y otro para toda la humanidad, proveniente

27 Cf. Orígenes, Ep. a Juliano 15.

28 Cf. Orígenes, Sel. Ps. 34,2.

29 Cf. Orígenes, C. Cels. 5,33.

30 Cf., p. e., Eusebio de Cesarea, Dem. 6,18,50; 9,13,15; Ecl. Proph. 3,18; 4,1; Com. Ps. 77,1; Com. Is. 1,26.

31 Cf., p. e., Eusebio de Cesarea, Laus Const. 16,1-2; Praep. 1,4,3-4; Com. Ps. 45,910; además Dem. 9,17,17-18. Esta focalización de las profecías veterotestamentarias en el poder imperial devenido cristiano será un tópico central en la controversia entre cristianos y judíos en Bizancio lcf., p. e., S. N. TRoIANOS, «Christians and Jews in Byzantium: A Love-Hate Relationship», en R. BonfIL / O. IRshal / G. G. StroumSA R. TALGAM [eds.], Jews in Byzantium. Dialectics of Minority and Majority Cultures [Jerusalem Studies in Religion and Culture 14]. Leiden-Boston, 2012, pp. 139-145; P. Magdalino / R. NeLSON, «Introduction», en ID. [ed.], The Old Testament in Byzantium [Dumbarton Oaks Byzantine Symposia and Colloquia]. Washington, D.C., 2010, pp. 12-15).

32 Cf. Basilio de Cesarea, HSab. 2. En la obra de dudosa autenticidad Enn. Is. se habla de la Palabra de Cristo, que alcanza a todo el mundo (cf., p. e., 2,72.74-75).

${ }^{33}$ Cf. Tertuliano, Ad. lud. 3,8-11 (nova autem lex clementiam designabat et pristinam ferocitatem gladiorum et lancearum ad tranquillitatem convertebat et belli pristinam in aemulos et hostes executionem in pacificos actus arandae et colendae terrae reformabat). 
del Dios bueno ${ }^{34}$; sino que muestra la unidad por el cumplimiento de la profecías en el Evangelio, así como la consecución de la paz anunciada en la vida de los creyentes ${ }^{35}$, y de ello ve un ejemplo en Pablo ${ }^{36}$. Este último tópico aparece también en Hipólito de Roma $(† 235)^{37}$.

Y si Cipriano $(† 258)$ solo cita dichos textos como expresión de la nueva Ley que debía darse ${ }^{38}$, Lactancio ( $\left.\dagger c a .320\right)$ hace lo mismo, pero, en el contexto de tensión con los judíos, subraya la superación del antiguo régimen por el nuevo ${ }^{39}$. Mientras que Hilario de Poitiers $(\dagger 367)$ señala que la predicación de la Palabra de Dios obtiene la salvación de los paganos que no había podido lograr la Ley ${ }^{40}$.

Agustín (†430) retoma todos estos tópicos exegéticos mencionados hasta aquí, pues recurre a Miq e Is para referirse a la fe cristiana, que procede de Jerusalén ${ }^{41}$, al llamado a los gentiles y su universalidad ${ }^{42}$, como advierte por caso en el letrero trilingüe de la $\mathrm{cruz}^{43}$. Pero sí precisa que todo ello se opone a los judíos ${ }^{44}$.

34 Cf. Tertuliano, Adv. Marc. 3,21,1: Sic nec illam iniectionem tuam potes sistere ad differentiam duorum Christorum, quasi ludaicus quidem Christus populo soli ex dispersione redigendo destinetur a creatore, vester vero omni humano generi liberando collatus sit a deo optimo. Discutiendo también sobre el dualismo, Metodio de Olimpo († 311) se refería a la profecía de Is para señalar que no existe el mal por naturaleza (cf. Autoex. 15,6-7).

35 Cf. Tertuliano, Adv. Marc. 3,21,2-3: Et erit, inquit, in novissimis diebus manifestus mons domini, utique sublimitas dei, et aedes dei super summos montes, utique Christus, catholicum dei templum, in quo deus colitur, constitutum super omnes eminentias virtutum et potestatum: también Adv. Marc. 4,1,4.

36 Cf. Tertuliano, Scorp. 13,1.

37 Cf. HıPólito, Ref. 6,16,5.

38 Cf. Cipriano, Test. 1,10.

39 Cf. Lactancio, Inst. 4,17,3-4; 4,17,8-21. Cf. además H. Schreckenberg, Die christliche Adversus-Judaeos-Texte, pp. 249-253.

40 Cf. Hilario, Ps. 52,18; $121,7$.

41 Cf., p. e., Agustín, C. Dei 10,32,2; 18,50; 18,54,1; Adv. lud. 7,9; Rep. Iul. 6,15.

42 Cf., p. e., Agustín, De op. mon. 21,25; Adv. Iud. 9,13; en relación con el mandato de bautizar (cf. Mt 28,19), cf. In 10. 6,9.

43 Cf., p. e., Agustín, Adv. Iud. 7,10: Ite nunc, o Israelitae secundum carnem, non secundum spiritum; ite nunc, et adhuc contradicite apertissimae veritati: et cum auditis: Venite, ascendamus in montem Domini, et in domum Dei lacob; dicite: Nos sumus; ut caeci offendatis in montem, ubi collisa facie peius perdatis frontem.

${ }^{44}$ Cf., p. e., Agustín, Sermo 218,6-7. En una ocasión señala que «el profeta [...] presenta a Cristo como un gran monte» (C. Dei 18,30,1: Michaeas propheta Christum in figura ponens magni cuiusdam montis [...]), detalle que también es señalado por Jerónimo, Ep. 78,22 (in Christo, monte pulcherrimo); Frg. Ps. 67 (214). Acerca de este 


\section{Acerca de Jr 38}

En cuanto a Jr 38,34 (LXX; 31,34 TM) -como ya señalé-, Leoncio se limita a comentar este pasaje mencionando los signos de Jesucristo, que habían acreditado su persona y misión, y de los que dan cuenta no solo las fuentes cristianas, sino también las judías y paganas ${ }^{45}$. Sobre este comentario acerca de las distintas fuentes que avalarían a Jesucristo es claro lo que hace a «los evangelios», y no es el caso señalar todas las posibles referencias en ellos al respecto. La dificultad reside en la alusión a las fuentes hebreas y griegas, en las que pone el acento el autor. En efecto, la vaguedad de la indicación y la ausencia de otros indicios en el escrito no permite mayores precisiones, sino solo evocar genéricamente posibles testimonios de los conocidos en la Antigüedad.

Así, para el caso de los «escritos cronísticos hebreos», se puede pensar por cierto en el Testimonium flavianum, que incluso en la lectura más restrictiva e independientemente de su autenticidad (pues no afecta a la coyuntura de Leoncio) habla de que Jesucristo no solo era un «sabio» y «maestro de la verdad», sino que llevó a cabo «grandes milagros» $\mathrm{y}$ «hechos maravillosos» ${ }^{46}$. Por su parte, en el Talmud de Babilonia (si bien sus partes son de difícil

tópico exegético del universalismo cristiano en contraposición con el particularismo en el judaísmo, cf., p. e., H. SchreCKENBERg, Die christliche Adversus-Judaeos-Texte, pp. 44-45, 47-58 launque la opinión general de este autor sobre Agustín en las páginas dedicadas al mismo en esa obra [352-362] debería matizarse con otras perspectivas, como, p. e., la ofrecida por B. BLumENKRANZ, «Augustin et les juifs. Agustin et le judaïsme», RechAug 1 [1958], pp. 225-241 [reimpreso en: Juifs et Chrétiens. Patristique et Moyen Age. Londres, 1977).

${ }^{45}$ Cf. Leoncio, Apol. 24-29; también supra n. 10.

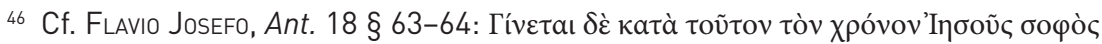

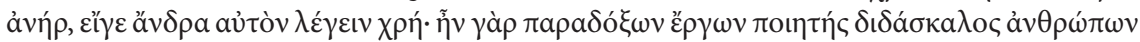

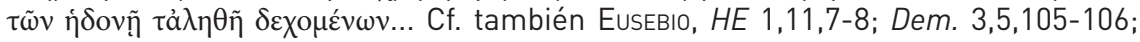
Theoph. 5,44; además E. Bammel, «Zum Testimonium Flavianum (Jos Ant 18,63-64)», en 0. Betz / K. HaAcker / M. Hengel (eds.), Josephus-Studien. Untersuchungen zu Josephus, dem antiken Judentum und dem Neuen Testament Otto Michel zum 70. Geburtstag gewidmet. Gotinga, 1974, pp. 9-22; R. PEnNA, Ambiente histórico-cultural de los orígenes del cristianismo. Textos y comentarios (Cristianismo y sociedad 39). Bilbao, 1994, pp. 307-309; A. WheAley, Joseph on Jesus. The Testimonium Flavianum Controversy from Late Antiquity to Modern Time. Frankfurt, 2003, passim; J. KLausner, Jesús de Nazaret. Barcelona - Buenos Aires, 1989, pp. 52-57; J. P. MEIER., Un judío marginal. Nueva visión del Jesús histórico. I. Las raíces del problema y la persona. Estella, 1998, pp. 79-108; F. BERMEJo RuBIO, «La naturaleza del texto original del Testimonium Flavianum. Una crítica a la propuesta de John P. Meier», en EstB 72 (2014), pp. 257-292; G. Theissen / A. Merz, El Jesús histórico. Manual. Salamanca, 1999, pp. 86-95; J. M. BLÁzquEZ, «Jesús», en Cristianismo primitivo y religiones mistéricas. Madrid, 1995, p. 81. 
datación) se hallan referencias a la libertad profética con que se desenvolvió Jesús y a su actividad como taumaturgo, y otras fuentes judías hablan de su (presunta) condición de «rey sabio» y de los portentos sucedidos en su deceso; naturalmente, todo ello sazonado con observaciones negativas ${ }^{47}$.

Más incierto aún es lo que se puede decir acerca de los «historiógrafos entre los griegos» que menciona Leoncio. Pues Dión Casio $(† 235)$ se refiere más bien a los cristianos; Galeno ( $\dagger c a$. 216) -que no era historiador- presenta una ligera equiparación de Cristo con Moisés; por su parte, Luciano de Samosata ( $† c a$. 180) -más bien literato- considera a Jesús como un «sofista crucificado», y el testimonio de Celso (siglo II), claramente negativo, señala que sobre la base de sus portentos se habría proclamado a sí mismo Dios ${ }^{48}$.

En la tradición exegética cristiana, este versículo no parece haber sido considerado de manera particular, menos aún en el sentido que se le da en la Apología. En efecto, solo es tenido como una profecía más que alude a la nueva economía de salvación que, luego, se realizó en Cristo, como por caso se lee en Cipriano de Cartago (†258), Eusebio de Cesarea (†339) y Jerónimo $(\dagger c a .420)^{49}$. Es cierto que en este último aparece asimismo alguna

47 Cf. Talmud Babilónico, Ab. Zarâ 16b-17a l= Toseftá Hulin 2,24; Sanhedrin 43a; también Mara bar Serapión, Ep.; Thallos, Frg. Icf. Orígenes, C. Cels. 2,33; Eusebio, Chr. 1,265); además, J. MAIER, Jesus von Nazareth in der talmudischen Überlieferung (EdF 82). Darmstadt, 1978, passim; J. P. MeIER, Un judío marginal I, pp. 112-118; J. KLausNER, Jesús de Nazaret, pp. 18-51; R. PenNA, Ambiente histórico-cultural, pp. 312-315, 319-321; G. Theissen / A. Merz, El Jesús histórico, pp. 95-99, 105-106; G. Barbaglio, Jesús, hebreo de Galilea. Investigación histórica. Salamanca, 2003, pp. 50-54; J. M. BLÁZquez, Jesús, p. 82.

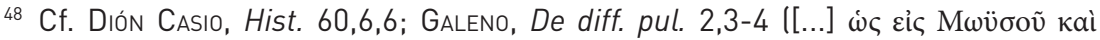

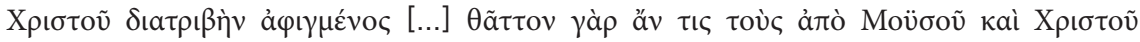

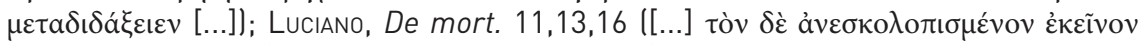

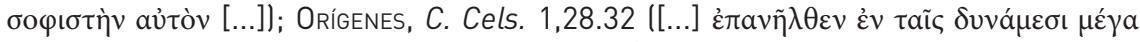

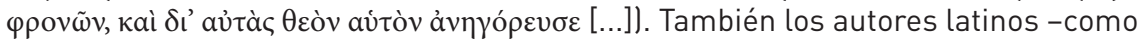
ya era el caso de otras fuentes judías- hablan preponderantemente de los cristianos, cf., p. e.: Plinio el Joven, Ep. 10,96; Tácito, An. 44,3-5; Suetonio, Claudio 25; EPICteto, Diatr. 2,9,19-21; 4,7,6; Marco Aurelio, Med. 11,3; Fronto de Cirta (cf. Minucio Félix, Oct. 8,4; 9,2-6). Cf., además, H. ConzeLmanN, Geschichte des Urchristentums (GNT 5). Gotinga, 1969, pp. 144, 146-150; R. PENNA, Ambiente histórico-cultural, pp. 314, 316319, 323-339, 340-342, 344-348; J. P. MEIER, Un judío marginal I, pp. 109-112; H. KösTER, Introducción al Nuevo Testamento. Historia, cultura y religión en la época helenística e historia y literatura del cristianismo primitivo (Biblioteca de Estudios Bíblicos 50). Salamanca, 1988, pp. 510-511; G. Theissen / A. Merz, El Jesús histórico, pp. 100105; G. Barbaglio, Jesús, pp. 45-50; J. M. Blázquez, Jesús, pp. 82-83.

49 Cf., p. e., Cipriano, Test. 1,11; Eusebio, Ecl. Proph. 1,37; Jerónimo, Adv. Jov. 2,27 (338). En Cipriano aparece también al hablar del fundamento de la esperanza y la fe lcf. 
invectiva contra los judíos, lo que se advierte, por ejemplo, en su Comentario a Jeremías, cuando de pasada menciona que la antigua Alianza fue invalidada por Israel, de donde su reprobación ${ }^{50}$. O también en su Comentario a Isaías, en el que remata sus consideraciones sobre la universalidad de la Iglesia señalando: «... a diferencia de los hebreos [...] nosotros de ningún modo buscamos en la tierra, sino en los cielos, la ciudad de Dios» ${ }^{51}$. Por su parte, Clemente Alejandrino ( $\dagger c a .215$ ), en el Protréptico, cita este pasaje de Jr como conclusión de su exhortación a conocer y contemplar a Dios, que en Cristo salva, instruye y diviniza ${ }^{52}$.

\section{En cuanto a Is 11}

$\mathrm{Al}$ pasar ahora a las consideraciones que hace Leoncio sobre «el signo del advenimiento de Cristo» conforme al texto de Is $11,6-8^{53}$, hay que recordar, ante todo, que parece haber sido común en la Antigüedad imaginar un estado primordial (o final) caracterizado por la armonía de la naturaleza: «Todos los seres [...] dóciles y acogedores para los hombres, las fieras y las aves, resplandecían por su disposición amistosa ${ }^{54}$, un reinado donde no cabe rastro del mal: «Todas las cosas sin insidias están llenas de paz» ${ }^{55}$; y a decir de Platón († ca. 347 a. C.), «dios mismo» es quien vela por

Test. 3,20), y Adamancio cita de pasada Jr, argumentando sobre la identidad del Padre de Cristo y el Creador (cf. Dial. 33). También en Minucio Félix hay una alusión (muy vagal al versículo de profeta, pero hablando de los castigos divinos (cf. Oct. 31,1-5).

${ }^{50}$ Cf. Jerónimo, Com. Jr. 6,26,1-9 (318-320): [...] tanta Dei in illo populo familiaritatis fuit, ut manu eum aprehendisse dicat et dedisse pactum, quod illi fecerunt irritum et propteres Dominus neglexit eos.

51 Jerónimo, Com. Is. 15,54,11-14 (623): [...] nequamquam nos iuxta Hebraeos [...] in terra, sed in caelis, urben Dei quaerentes [...].

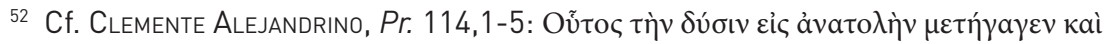

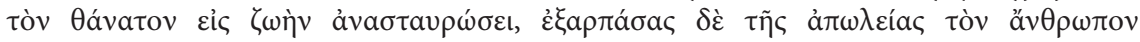

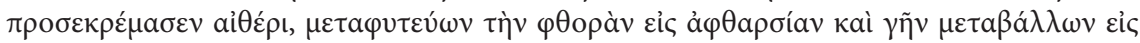

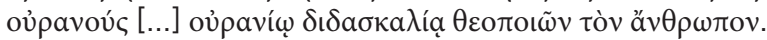

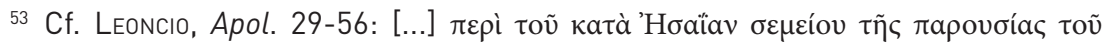

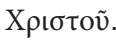

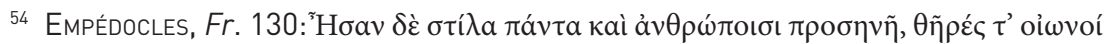

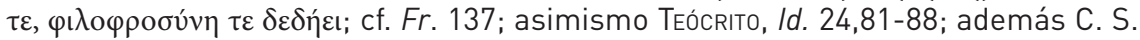
KIRK / J. E. Raven / M. Schonfield, Los filósofos presocráticos. Historia crítica con selección de textos II. Madrid, ${ }^{21997, ~ p p . ~ 427-428 . ~}$

55 OviDIo, Met. 15,96-103: Cuncta sine insidiis nullamque timentia fraudem / plenaque pacis erant; cf. también Met. 1,101ss; además HorAcIo, Ep. 16,50-54; VIRGILIO, Eclg. 4,18-30; 5,60-61. 
tal bienestar y abundancia ${ }^{56}$. Que un atisbo de tal bonanza se hacía ya presente en figuras destacadas parece ser lo que insinúa Jámblico ( $† c a .330$ ) al hablar de Pitágoras $(\dagger c a .475 \text { a. C. })^{57}$. Una visión similar, pero más orientada hacia el final de la historia, se habría dado también en ambientes judíos, a juzgar por el testimonio de Filón ( $† c a$. 45), que describe el imperio del hombre sobre las bestias salvajes ${ }^{58}$, e igualmente de Jerónimo $(\dagger c a$. 420) que, hablando expresamente del oráculo de Is 11, precisa: «Los judíos [...] sostienen que [...] esto sucederá según la letra en la manifestación del Mesías [...] al final de los tiempos» ${ }^{59}$. Comprensión que luego, en el ámbito cristiano, habría sido particularmente apreciada por los milenaristas, como se advierte en el recién citado Jerónimo e igualmente en Ireneo de Lyon $(\dagger c a .202)$ y en Lactancio $(\dagger c a .320)^{60}$.

Pero la lectura del oráculo profético es mucho más variada aún en los autores cristianos, que recurren a menudo a él, tanto de manera general $^{61} \mathrm{o}$ interpretándolo detalladamente, como hace Leoncio ${ }^{62}$, e incluso, al igual que este, relacionándolo, por ejemplo, con el Sal 48(49),13.21, con Is 43,20 o con otros textos de la Escritura ${ }^{63}$. Y conociendo igualmente el problema ya mencionado (especialmente con los judíos) del evidente no cumplimiento literal del pasaje bíblico ${ }^{64}$, los escritores cristianos propusieron

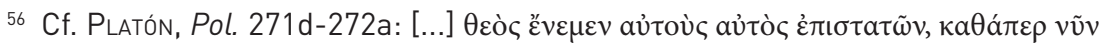

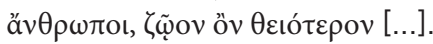

57 Cf. JÁmBlico, Vit. Pyth. 24.

58 FILón, De praem. 85-90.

59 Jerónimo, Com. Is. 4,11,6-9 (150): Haec quoque ludaei [...] iuxta litteram futura contendunt, ut in claritate Christi [...] in fine mundi [...]; cf. también 18,23 (768); además Orígenes, De Princ. 4,2,1; asimismo Orac. Syb. 3 lal respecto también A. Díez MaCho [ed.], Apócrifos del Antiguo Testamento III. Madrid, 1982, p. 312).

60 Cf. Jerónimo, Com. Is. 4,11,6-9 (150); 18,23 (768); Ireneo, Dem. 61; Lactancio, Inst. 7,24,7-12; Epit. 67(72),1-5.

${ }^{61}$ Cf., p. e., Ireneo, Dem. 61; Adv. haer. 5,8,3; 5,33; Tertuliano, Herm. 11,3; Adv. Marc. 4,24,9-10; Clemente Alejandrino, Str. 3,67,2; 3,102,3; Paed. 1,101,3; Orígenes, C. Cels. 4,93; Com. Io. 13,32,203-213; Hom. Ez. 11,3; Lactancio, Inst. 7,24; Eusebio de CeSarea, Com. Ps. 68.22-25.35; Ecl. Proph. 4,8; Dem. 2,3,111; 3,2,40-42; 7,3,34-36; CIRIlo de Jerusalén, Cat. 17,10; Gregorio de Nacianzo, Carm. hist. 1,12 (PG 37, 1168); Gregorio de NisA, In Cant. 14 (GNO 6,424); Ambrosio, De Interp. 4,1,4-5; De Paen. 1,13; Com. Ps. 37,4; Gregorio de Elvira, Trac. 5,36; Jerónimo, Ep. 106,1.

${ }^{62}$ Cf., p. e., Clemente Alejandrino, Str. 4,12,1; 6,50,1-6; Lactancio, Epit. 67(72),4-5; Ambrosio, Hex. 6,3; Teodoreto de Ciro, Com. Is. 11,6.

${ }^{63}$ Cf., p. e., Ireneo, Adv. haer. 4,41,3; 5,8,2-3; Clemente Alejandrino, Str. 3,67,2; 3,102,3; 4,12,4; 6,50,2-6; Paed. 1,101,3; Orígenes, C. Cels. 4,90.

${ }^{6}$ Cf., p. e., Orígenes, De Princ. 4,2,1. 
una interpretación en dos niveles, y esto ya desde muy temprano, a juzgar por el testimonio de Ireneo de Lyon ( $\dagger c a .202)$, que remonta esta forma de lectura a «los presbíteros»y, por ellos, hasta el apóstol Juan y el mismo Señor ${ }^{65}$. De este modo habría una interpretación «en símbolo» del texto de Is 11 , porque «los hombres, venidos de gentes varias», alcanzan «la unidad de la fe», «cambiando su naturaleza salvaje y feroz». Pero, «aunque esto ocurra ahora [...] también se cumple en la resurrección de los justos», esto es, cuando la creación vuelva a su condición originaria, y entonces, «en verdad», «todos los animales obedezcan y estén sometidos al hombre [...] y vuelvan al alimento que primero les otorgó Dios» ${ }^{66}$.

Con todo, la exégesis más habitual en la tradición cristiana parece olvidar la perspectiva escatológica y centrarse en la realización de la profecía veterotestamentaria en la humanidad por la venida de Cristo, esto es, en la Iglesia, para lo que se recurre profusamente a la interpretación alegórica de diversos elementos del texto bíblico, tal como hace Leoncio en el fragmento aquí considerado. Así, para empezar, es común, en general, considerar los distintos tipos de animales como imágenes de variados caracteres humanos ${ }^{67} \mathrm{y}$, consecuentemente, destacar que por la conversión a la fe, la

${ }^{65}$ Cf. Ireneo, Adv. haer. 5,33,3: Quemadmodum Presbyteri meminerunt, que Johannem discupulim Domini viderunt, audisse se ab eo quemadmodum de temporibus illis docebat Dominus et dicebat [...]; también 5,33,4; Dem. 61 [«enseñan los presbíteros»); además A. ORBE, Teología de san Ireneo. Comentario al Libro V del «Adversus haereses» III (BAC maior 33). Madrid-Toledo, 1988, pp. 416-418, 426429; E. Romero Pose, Ireneo de Lión. Demostración de la predicación apostólica (Fuentes Patrísticas 2). Madrid, 1992, pp. 177-178.

66 IRENEO, Adv. haer. 5,33,4: Sed etsi nunc hoc sit in quibusdam hominibus ex variis gentibus in unam sententiam fidei venientibus, nihilominus in resurrectione justorum super his animalibus [...] Et oportet conditione revocata obaudire et subjecta esse omnia animalia homini et ad primam a Deo datam reverti escam. Cf. también IRENEO, Dem. 61: «En cuanto al entendimiento, la concordia y la paz entre los animales [...] enseñan los Presbíteros que así será en verdad a la venida de Cristo [...] Pues ya [aquí] en símbolo da a conocer que los hombres de razas diferentes [...] se juntarán en la concordia y la paz [...] Esto es lo que ha ocurrido ya, pues los que antes eran crudelísimos [...] una vez instruidos sobre Cristo y creído en él, han dado fe todo a una y han cambiado [...]». Cf. además A. ORBE, Teología de san Ireneo III, pp. 438-443; E. Romero PoSe, Ireneo de Lión. Demostración, pp. 177-180.

67 Cf., p. e., Ireneo, Dem. 61; Adv. haer. 4,4,3; 4,41,3; 5,8,2-3; Clemente Alejandrino, Str. 3,67,2; 3,102,3; 4,12,1; Paed. 1,101,3; Orígenes, C. Cels. 4,90.93; In. Cant. 3 (2,9); In Ez. 14,4 (J. B. Pitra, Analecta Sacra III. París, 1883, p. 545); Sel. in lob 35,11; BASILIO De CeSAReA, HPs. 48,9.11; Hex. 9,2; HEbr. 3; Pseudo Basilio, Enarr. Is. 1,14; C. Eun. 5 (PG 29, 728 A); Gregorio de Nisa, Insc. 2,12 (GNo 5,131); Eusebio de Cesarea, Com. Ps. 72,18-20; 77,39; 48,13-14 (J. B. Pitra, Analecta Sacra III, p. 427); Agustín, C. Dei 13,3; Enarr. Ps. 48,1,16; Sermo 233,3; Ambrosio, Exp. Ps. 48,20.26-27; Cain 2,1,3; Com Lc. 7,76; Jerónimo, Ep. 98,4; 
predicación o la enseñanza del cristianismo llegan a conformar el único rebaño de la Iglesia ${ }^{68}$.

Y para continuar ilustrando con algunos detalles de dicha alegorización de Is 11 se pueden señalar algunos ejemplos y decir, por caso, que Leoncio ve en el «lobo» del texto bíblico «al que está presto para arrebato»

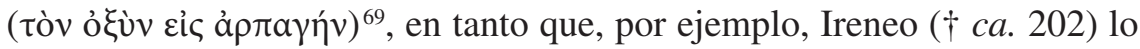
relacionaba con la codicia y Clemente Alejandrino ( $\dagger c a$. 215) con quien es avaro $^{70}$. Muy cercana parece la interpretación de Basilio de Cesarea $(\dagger$ 379), como también la de Teodoreto de Ciro ( $\dagger c a$. 466), que ven en ese animal una figura de quien es rapaz ${ }^{71}$; mientras que Jerónimo $(\dagger c a .420)$ lo lee junto con el leopardo como imagen de los que engañan, imitando la inocencia de sus presas ${ }^{72}$. Por su parte, el «cordero» habla para Leoncio de «quien

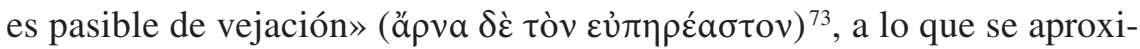
ma la lectura de Teodoreto, que tiene a la «oveja» por ejemplo de mansedumbre, mientras que Ambrosio, curiosamente, ve en ese animal la figura de quienes están vueltos hacia las cosas terrenas ${ }^{74}$.

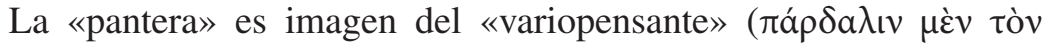
$\pi$ roıkı $\lambda$ ó $v \omega \mu \mathrm{ov})$, según Leoncio, y en esto se le asemeja Teodoreto de Ciro $(\dagger c a .466)$, que destaca el aspecto «variopinto» de ese animal ${ }^{75}$; en tanto que Ireneo (†ca. 202) sentencia que «las mujeres eran como leopardos y

Com. Is. 13,50,1 (550); Com. Ez. 4,14,1-11 (152); 10,32 (449); Com. Jr. 1,94,2-3 (55); por su parte, Tertuliano interpreta como distintos malos espíritus (cf. Adv. Marc. 4,24,10).

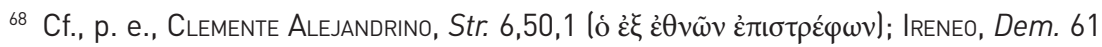
[«gracias al nombre de Cristo», «por la gracia de Dios», «instruidos sobre Cristo y creído en él», «la mudanza que la fe en Cristo [...] opera»); Adv. haer. 5, 33,4 (credentes et cum crediderint consentientes justis [...] in unam sententiam fidei); TERTULIANo, Adv. Marc. 4,24,10; OríGENES, Hom. Ez. 11,3 (cum autem fuerit tam diversaruminter se naturarum in

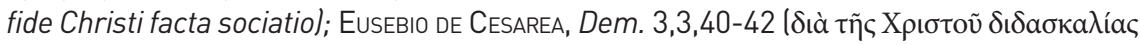

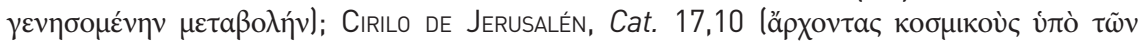

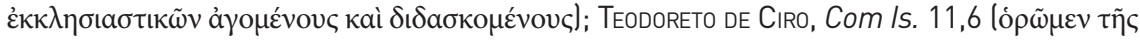

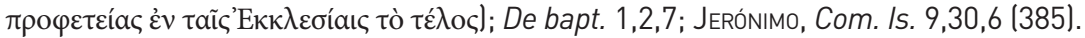

69 LeONCIO, Apol. 32.

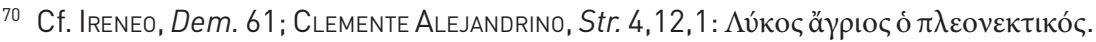

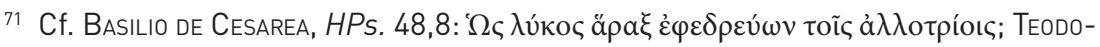

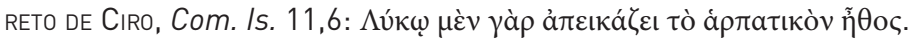

72 Cf. Jerónimo, Com. Is. 4,11,6-9 (152): [...] lupus et pardus agni et haedi imitentur innocentiam.

73 LeONCIO, Apol. 33.

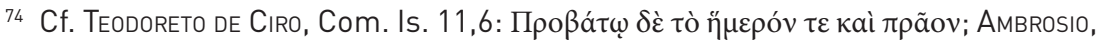
Hex. 6,3,10: Caue, o homo, pecorum more coruari, caue in aluum te non tan corpore quam cupiditate deflecta.

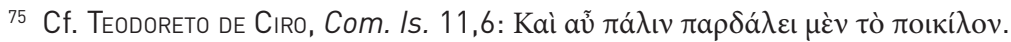


víboras», aunque luego solo se detiene a hablar de estas últimas ${ }^{76}$. Igualmente similar a Teodoreto es la interpretación del «cabrito» como «el sim-

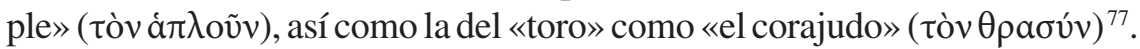
En tanto que lo que se dice sobre el «león», a saber, que es imagen del «so-

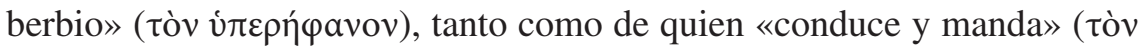

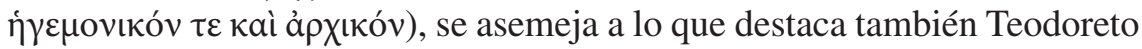
o asimismo Ambrosio de Milán $(† 397)^{78}$. Sí cabe decir algo más respecto de los «áspides intelectuales» ( $\tau \tilde{\omega} v v o \eta \tau \tilde{\omega} v a ̉ \sigma \pi i ́ \delta \omega v)$, que Leoncio tiene por imágenes de «los demonios lanzavenenos y mortíferos» ( $\tau \tilde{\omega} v$ loßó $\lambda \omega v$ kà

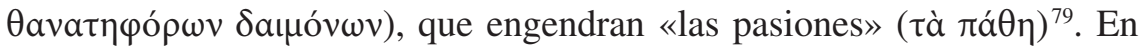
efecto, ya se mencionó que Ireneo habla de algo semejante al referirse a la pantera, y lo relaciona con las mujeres ${ }^{80}$; en tanto que Clemente ( $\dagger c a .215$ ) consideraba a la serpiente como «el mentiroso» ${ }^{81}$, asemejándose así a lo que Hilario (esta vez hablando de Os 2,20) sostiene: son «los que tienen en su cuerpo un alma envenenada y mentirosa» ${ }^{82}$.

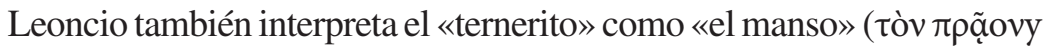

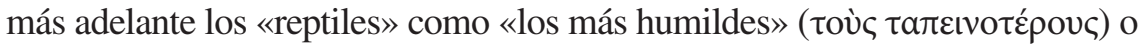

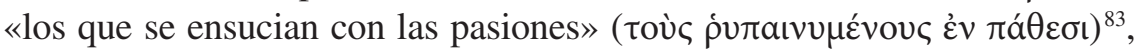
alegorías que no me constan en otros autores cristianos antiguos.

Por su parte, Clemente Alejandrino ( $\dagger c a .215)$ considera al «buey» de la profecía de Is como «el judío [...] uncido al yugo de la ley [...] animal puro», en tanto que a la «osa», «animal impuro y salvaje», la tiene por imagen del «gentil que se convierte» ${ }^{84}$. En tanto que Leoncio considera al pri-

76 IRENEO, Dem. 61.

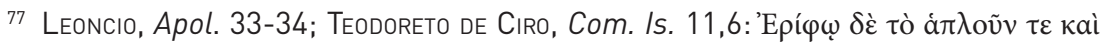

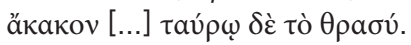

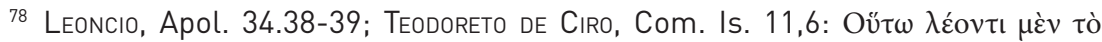

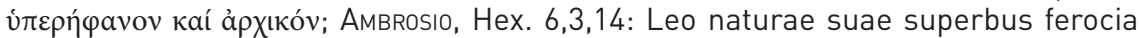
aliarum ferarum generibus miscere se nescit, sed quasi rex quidam plurimorum dedignatur consortium. Cf. también S. HEYDASCH-LEHMANN, «Panther (Leopard)», en RAC 25 (2014), pp. 913-914.

79 LeOncio, Apol. 43-44.

80 Cf. supra n. 76.

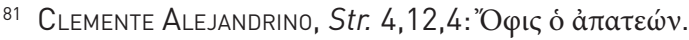

82 Hilario de Poitiers, De Myst. 2,2: [...] et cum serpentibus terrae, nempe uenenato animo atque fallente in corpore constitutus.

83 LeONCIO, Apol. 34.50-51.

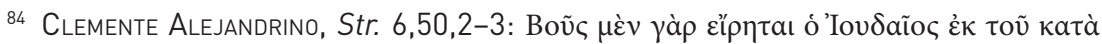

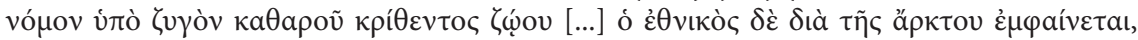

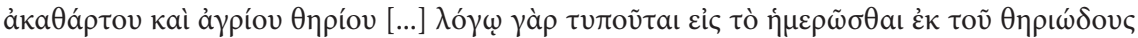

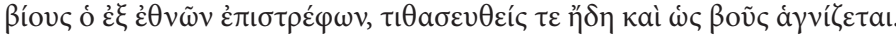


mero como «el trabajador» (

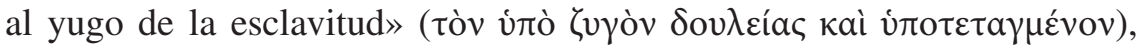

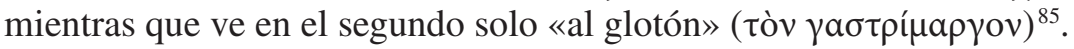

En el fragmento de la Apología contra los judíos, las «fieras del

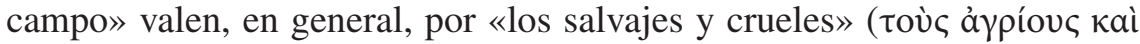

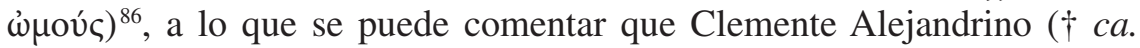
215) agregaba que son «salvajes respecto de la fe, poco pulidos en cuanto a la vida y no purificados según la Ley» ${ }^{87}$. Y en cuanto a las «aves», que

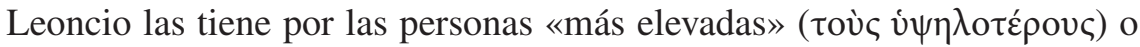

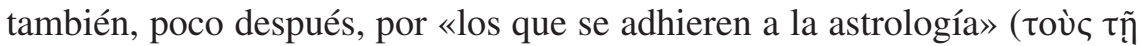

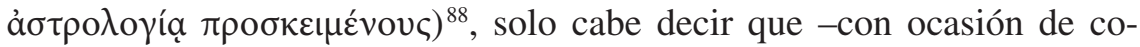
mentar Os 2,20- Hilario de Poitiers $(† 367)$ ve en ellas simplemente «a los que viven en la vanidad de este mundo» ${ }^{89}$.

En cuanto al que conduce y apacienta a todos esos animales, siguiendo a Is 11, Leoncio lo tiene por un «niño» ( $\pi$ aĩs), que interpreta como al-

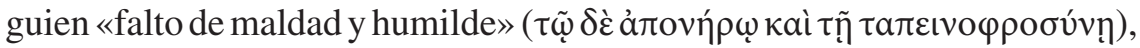

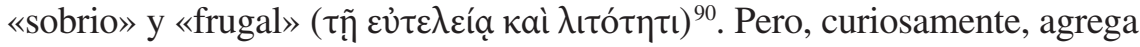
a esa figura el detalle de que se trata también de un «hombre canoso» (äv $\theta \rho \omega \pi \circ \varsigma[\ldots] \pi$ o $\left.\lambda_{\imath o ́} \varsigma\right)$, teniéndolo entonces por imagen de «la sensatez» $(\tau \tilde{n}$ [...] $\varphi \rho o v \eta ́ \sigma \varepsilon \iota)$ y de «la virtud» $(\tau \tilde{n} \text { ả } \rho \varepsilon \tau \tilde{n})^{91}$. Solo aparece algo comparable en Jerónimo ( $\dagger c a .420$ ), que habla de un «niño, pequeño en malicia», que ahuyenta a los demonios ${ }^{92}$. En tanto que, por lo que hace al alimento de esos animales, la «paja», Leoncio únicamente precisa que se trata de «la

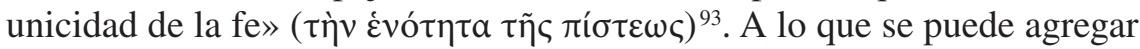
que, en su Pedagogo, Clemente Alejandrino ( $\dagger c a$. 215) hablaba de ella como la «justicia de Dios» ${ }^{94}$, mientras que Jerónimo solo indicaba que era

85 LeONCIO, Apol. 38-39.

86 LeONCIO, Apol. 49.

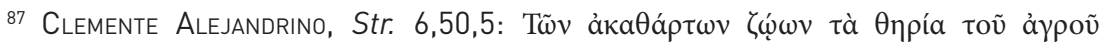

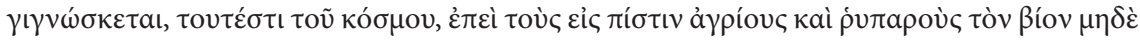

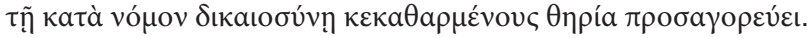

88 LEONCIO, Apol. 49-50.

89 Hilario de Poitiers, De Myst. 2,2: [...] et cum uolatilibus cæli, scilicet sub inanitate mundi huius et uacuitate uiuentibus.

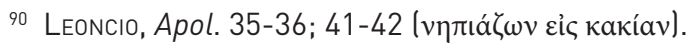

91 LeONCIO, Apol. 35-36.

92 Jerónimo, Com. Is. 4,11,6-9 (152): Infans quoque, quia malitia paruulus est, mittit manum in foramine aspidis, et de obsessis hominum corporibus fugat demones.

93 LeONCIO, Apol. 40-41.

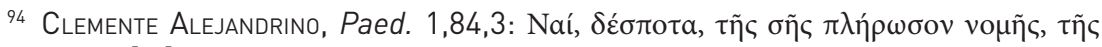

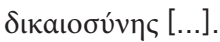


un «alimento sencillo» ${ }^{95}$, en tanto que Orígenes ( $\dagger c a$. 254), en su consideración sobre los distintos alimentos a partir de Jn 4,32, si bien menciona el pasaje de Is, no hace ninguna indicación particular al respecto ${ }^{96}$.

\section{A modo de conclusión}

No es mucho el volumen de material a disposición en este fragmento de la Apología contra los judíos como para aventurar grandes consideraciones acerca de la exégesis de Leoncio de Neápolis, pero quizá cabe decir, aunque más no sea un par de palabras, sobre el tratamiento que el autor hace de los pasajes veterotestamentarios. Ante todo, que su exégesis no parece aventurarse por ninguna nueva senda que no hubiera sido ya recorrida por los autores cristianos anteriores a él. Solo en el caso de alguna lectura alegórica concreta del pasaje de Is 11 no fue fácil encontrar antecedentes ${ }^{97}$.

Y, a propósito de esto, es oportuno destacar que en Leoncio es tal interpretación alegórica la que determina la exégesis, en orden a legitimar la pretensión cristiana del advenimiento ya cumplido del Mesías en Jesucristo. En este sentido se debe notar que aquí no parecen quedar rastros de ninguna apertura a un cumplimiento escatológico al final de la historia de los pasajes bíblicos en cuestión, enfoque de largo alcance que sí estaba presente en autores anteriores, tal como es el caso de Justino, para la lectura de Miq 4 e Is 2, con su noción del «doble advenimiento de Cristo», o de Ireneo de Lyon, para la de Is 11, con la apelación a la reconstitución cuando «la resurrección de los justos» ${ }^{98}$. Esto mismo bien podría ser un indicio de que la argumentación se centra en la actualización eclesial de los textos bíblicos en cuestión más que en la dimensión histórica de mayor amplitud, una suerte de acentuación eclesiológica que deja en un cono de sombra una visión de la teología de la historia de más envergadura. Pero precisamente tal parece ser la intención del autor en este pasaje, esto es, que tal forma de proceder le confiera una consistencia inexorable a la refutación de la objeción implícita del oponente.

Alberto C. CapboscQ, SBD

95 Jerónimo, Com. Is. 4, 11,6-9 (152): Leo quoque non carnes comedet, sed paleas, quod scilicet uescatur cibo simplici.

96 Cf. Orígenes, Com. 10. 13,32,203-213.

97 Cf. supra p. 10.

${ }_{98}$ Cf. supra pp. 3 y 8 respectivamente. 